\section{P103 INCREASING STI DIAGNOSIS, TREATMENT AND AWARENESS AT THE WORLD'S LARGEST ANNUAL SEXUALITY AND LIFESTYLE CONVENTION WITH THE AID OF POINT-OF-CARE TESTING}

Rosemarie Turner*, Sara Day, Katie Allen, Emma Ostridge, Kate Nulty, Grainne Cooney, James Hardie, David Payne, Ella Svensson, Temi Lampejo. Chelsea and Westminster Hospital NHS Foundation Trust, London, UK

\subsection{6/sextrans-2016-052718.157}

Background Sexpo is the largest sexual health and lifestyle exhibition in the world. It launched in the UK (London) in November 2015.

Aim Raise sexual health awareness and offer STI screening to attendees identifying whether these clients attend mainstream GUM services.

Methods A health bus was stationed inside the exhibition where attendees and exhibitors received a sexual health consultation and free STI testing (including HIV point of care tests), condoms and contraceptive information. Interactive seminars, covering common sexual health and contraceptive themes, were delivered by our team of five nurses, two health advisers, one doctor and one event co-ordinator.

Results 205 patient consultations occurred. These were 56\% (114) male, 44\% (89) female and a median age 33 years. Most clients were white British, 51\% (104), or white Other, 23\% (47). 77\% (156) identified as heterosexual, 10.8\% (22) bisexual women, 9.9\% (20) MSM, 0.5\% (1) WSW and 2\% (4) declined to answer. 5\% (12) identified as swingers. $100 \%$ were offered an HIV test, 188 (94\%) accepted. 31.5\% (64) clients had never tested for HIV before. 199 clients accepted either HIV or STI testing: of these 5\% (10) were diagnosed with an STI. All patients with an STI were offered treatment. 3\% (6) clients reported hazardous use of drugs.

\begin{tabular}{lc} 
Abstract P103 Table 1 & STI diagnoses at Sexpo \\
\hline STI & $\%(\mathrm{~N})$ \\
\hline Syphilis & $0.5 \%(1)$ \\
Hepatitis B & $0.5 \%(1)$ \\
Hepatitis C & $0.5 \%(1)$ \\
Chlamydia & $3.5 \%(7)$ \\
\hline
\end{tabular}

Discussion Visitors to this exhibition found our opportunistic sexual health screening acceptable. Up to $15 \%$ of our clients were amongst high risk groups and 1 in 20 clients were diagnosed with an STI. 31.5\% (64) clients had not accessed mainstream GUM services before.

\section{P104 MANAGEMENT OF CHRONIC PROSTATITIS IN AN INNER LONDON SEXUAL HEALTH CLINIC}

Mohamed Abdulcadir*, Rosemarie Turner, Temi Lampejo. Chelsea and Westminster Hospital NHS Foundation Trust, London, UK

10.1136/sextrans-2016-052718.158

Introduction Chronic prostatitis is a distressing condition with significant impact of quality of life. Chronic prostatitis (CP) symptoms include pain, urinary symptoms and sexual dysfunction. The prevalence of prostatitis is approximately $5-9 \%$ in the general population. This retrospective case study evaluated the management of this condition using the NIH -Prostatitis symptoms index (NIH-CPSI) and UPOINT involving 6 domains (urinary, psychological, organic-specific, infection, neurological/ systemic, tenderness) to stratify patient into specific symptomsled phenotypes.

Method The symptoms of patients were captured using the NIH- CPSI scores and the UPOINT diagnostic algorithm addressing CP phenotypic domains according to the likely aetiology mechanism (3). NIH-CPSI is used to measure the severity of CP symptoms, encompassing 13 items grouped into three domains: pain, urinary symptoms and quality of life (QOL). The highest score is 43; a high score indicates a worse outcome. A reduction of 6 points after treatment is considered a good response.

Results 28 patients were seen over 6 months. 57\% (16) were new diagnoses and 43\% (12) were recurrent. All patients were treated with ciprofloxacin except when gram positive bacteria were detected and Co-Amoxiclav was prescribed. The average reduction in NIH-CPSI score after treatment was 11.5.

Conclusion; In our cohort a significant proportion of men responded to antibiotic because of positive bacterial culture in the semen. A quarter of patients had a combination of antibiotics and anti-inflammatories. Patient with voiding difficulties were referred to the urology team, those with psychological problems, were referred to the psychology team.

\section{P105 A BESPOKE SEXUAL HEALTH SERVICE FOR TRANSGENDER PEOPLE IS HIGHLY ACCEPTABLE AND MEETS THE BROADER HEALTH NEEDS OF THIS POPULATION}

${ }^{1}$ Bethan Machado*, ${ }^{1,2}$ Kate Nambiar, ${ }^{2}$ Tamara Woodroffe, ${ }^{2}$ Alison Parnell, 1,2Daniel Richardson. 'Brighton and Sussex Medical School, Brighton, UK; ${ }^{2}$ Brighton and Sussex University Hospitals NHS Trust, Brighton, UK

10.1136/sextrans-2016-052718.159

Background/introduction As part of a local health inequalities study Clinic-T was established in the summer of 2012 in partnership with Brighton LGBT Health Inclusion Project and Terence Higgins Trust to meet the sexual health and broader needs of transgender (trans) patients. Services provided include STI testing and treating, contraception advice, post-exposure prophylaxis, and supporting psychological and medical aspects of transitioning.

$\operatorname{Aim}(\mathbf{s}) /$ objectives To evaluate the current service within Clinic-T, specifically relating to the care and management of trans patients.

Methods Patients attending Clinic-T on 25th November 2015 and 4th February 2016 were asked to complete a fifteen-question satisfaction survey.

Results 14 patients returned surveys. Median age 32 (IQR 2542). All participants were White British. The self-reported gender identities were: Non-binary 6/14 (43\%), Trans - not specified $3 / 14$ (21\%), Male (including trans male) 3/14 (21\%), and Female $2 / 14$ (14\%). $50 \%$ of respondents were new patients. $50 \%$ of patients had discussed their trans health concerns with their GP: $72 \%$ were satisfied with the GP consultation. 11/14 (78\%) included sexual health as a reason for attending. 5/11 patients also attended for their general health/psychological issues/hormonal treatment. 7 aspects of patient satisfaction were assessed with all but 1 of those who responded giving the maximum rating. $14 / 14$ recommended the service to family or friends (FFT).

Discussion/conclusion Clinic-T appears to be addressing the needs and expectations of the trans community and scored 
highly on the FFT. Working in partnership with local charitable organisations underpins working with difficult to reach groups.

\section{P106 ENSURING STAFF TRAINING IN INTEGRATED GUM SERVICES IN TRANSGENDER HEALTH ISSUES IS IMPORTANT: SEXUAL HEALTHCARE PROFESSIONALS (HCP) WANT SMALL GROUP TEACHING}

${ }^{1}$ Bethan Machado*, ${ }^{1,2}$ Kate Nambiar, ${ }^{1,2}$ Daniel Richardson. ${ }^{1}$ Brighton and Sussex Medical School, Brighton, UK; ${ }^{2}$ Brighton and Sussex University Hospitals NHS Trust, Brighton, UK

\subsection{6/sextrans-2016-052718.160}

Background/introduction Locally there is a large transgender (trans) population. As part of a health inequalities initiative in 2012 a bespoke sexual health service for trans patients (Clinic-T) was set up. This included HCP training.

Aim(s)/objectives To evaluate the current service relating to care and management of trans patients within the Claude Nicol Centre.

Methods Online survey - emailed to all staff between February and March 2016.

Results 45 HCP completed the survey. Job roles were: Doctor 21/45 (47\%), Nurse 17/45 (38\%), Health Advisor 3/45 (7\%), HCA 1/45 (2\%), Admin/Reception staff 3/45 (7\%). 31/45 (69\%) of the respondents had been working in sexual health for at least 6 years. The majority of respondents, 36/44 (82\%), do not see patients during Clinic-T. However, 16/45 (36\%) see trans patients at least three monthly and 29/45 (64\%) see trans patients less frequently than every 6 months. 33/43 (77\%) of HCP did not feel confident about seeing trans patients in a clinical setting - specific aspects include: 21/42 (50\%) understanding sexual health needs, 35/43 (81\%) where to seek gender reassignment advice, 40/43 (93\%) seeking hormonal replacement therapy advice, 32/43 (74\%) addressing psychological issues, and 34/ $43(79 \%)$ providing additional support in the community. The majority of HCP 26/45 (58\%) would like further training to be delivered through small group teaching.

Discussion/conclusion The majority of HCP are not confident when approaching trans patients at work. With a significant number of HCP seeing trans patients in general clinics it is important to ensure that broader sexual health services are acceptable to the local trans population. Programmes of education are needed to underpin quality improvement.

\section{P107 IDENTIFYING ABUSE IN SEXUAL HEALTH SETTINGS - HOW WELL ARE WE DOING?}

Arnold Fernandes*, Alison Squibb, Joanna Fitzgerald, Alison Brazington, Kate Horn. Royal United Hospital, Bath, UK

\section{$10.1136 /$ sextrans-2016-052718.161}

Background/introduction There is increasing evidence to suggest that individuals, who have encountered abuse of any nature, may present in a variety of health care settings and with a multiplicity of symptoms without disclosing the fact that the underlying reason for their presentation is abuse. In 2015 we introduced a prompt in our template to encourage professionals to raise the issue of abuse with all attendees to our unit.

Aim(s)/objectives Our aim was to assess how often abuse was disclosed, identify the nature of the abuse and offer support when this was requested.
Methods Retrospective review of all attendees to the Walk-in sessions over the course of a month in February 2016. A total of 106 notes were reviewed.

Results Of the 106 attendees interviewed, 8 (13.25\%) reported abuse. Of these, 6 were women and 2 were men. In all cases the abuse was disclosed, only on direct questioning. All 8 cases reported historical abuse. Physical and emotional abuse, were commonly reported. 3 of the women were aged between 21-30 years and 2 between 51-60 years. The men were aged 21 and 41. All attendees were offered the option of referral for further support, but all declined as all felt that they had either received support previously or had the opportunity to get over the trauma of what they had encountered.

Discussion/conclusion This audit demonstrates that abuse is common among attendees to Sexual health. This may not be disclosed unless raised as a matter of routine.

\section{P108 CAN INTEGRATED SEXUAL HEALTH SERVICES FUNCTION EFFECTIVELY WITHOUT A HEALTH ADVISOR?}

Jennifer McCay. Bridgewater NHS Trust, Trafford, Uganda

10.1136/sextrans-2016-052718.162

Background/introduction Four services merged to create one integrated sexual health service. The service is operating without a health advisor. Basic health advising duties are carried out by nursing staff.

Aim(s)/objectives Assess the effectiveness of current practice in relation to adherence to BASHH PN standards and consider changing practice and/or service provision if adherence is found to be poor.

Methods The inclusion criteria is any patients attending the service 01/08/2015-30/09/2015 who had a C4 diagnosis. The notes were reviewed retrospectively and the level of PN was checked against BASHH standards.

Results 90 patients were in the sample. 96\% of patients had PN discussed at the time of treatment. 57\% had PN agreed for each contact and PN outcomes documented, 0.66 contacts per index patient were reported as attended, 0.3 contacts per index patient were verified at attended, $79 \%$ of patients had a follow-up compliance check.

Discussion/conclusion Adherence to BASHH PN standards was better than expected. Measures were taken to improve adherence including prompts on the new EPR system to initiate and review PN. The recalls policy was updated and a compliance check proforma was introduced. The audit demonstrated the need for a health advisor within an integrated sexual health service. Recruitment of a new health advisor for the service has commenced.

\section{P109 THE SANTÉ PROJECT: ATTITUDE TOWARDS STI RISK ASSESSMENT, PREFERENCES FOR STI BEHAVIOURAL RISK REDUCTION INTERVENTIONS: SERVICE USERS PERSPECTIVES}

\footnotetext{
${ }^{1}$ Anupama Roy*, ${ }^{2}$ Carina King, ${ }^{3}$ Alec Miners, ${ }^{1}$ Carrie Llewellyn, ${ }^{1}$ Alex Pollard, ${ }^{2}$ Richard Gilson, ${ }^{1,4}$ Daniel Richardson, ${ }^{4}$ Laura Clark, ${ }^{2}$ Fiona Burns, ${ }^{2}$ Alison Rodgers, ${ }^{2} J u l i a$ Bailey, ${ }^{2}$ Maryam Shahmanesh. 'Division of Primary Care and Public Health, Brighton and Sussex Medical School, Brighton, East Sussex, UK; ${ }^{2}$ Research Department of Infection and Population Health, University College London, London, UK; ${ }^{3}$ Department of Health Services, London School of Hygiene and Tropical Medicine, London, UK; ${ }^{4}$ Brighton and Sussex University Hospital NHS Trust, brighton, East Sussex, UK
}

10.1136/sextrans-2016-052718.163 